\title{
REFORM AND INNOVATION IN NEW PERIOD: AN ANTHROPOLOGICAL STUDY OF CHAOSHAN CHAMBERS OF COMMERCE IN SHENZHEN
}

\author{
Xie Shunlong, Lin Bo \\ SHANTOU UNIVERSITY BUSINESS SCHOOL
}

\begin{abstract}
In order to probe the mechanism of reform and development of the Chaoshan Chamber of Commerce in Shenzhen City (CCCSC), this paper applies anthropological methods to construct a case study on the basis of qualitative multiple-level data. The innovation of the CCCSC in its operation is concerned with three important aspects of the reform, including strategic basis, financial strategy and organizational structure. There exist several factors of both motivation and resistance in its internal mechanisms. The reform practice of the CCCSC provides new information for academic research on the governance of Chambers of Commerce, and learning experiences to innovate governance patterns for many non-local chambers of commerce.
\end{abstract}

Keywords: operational pattern, organizational reform, non-local chamber of commerce

\section{Introduction}

As an intermediary organization between government and enterprises, a chamber of commerce has always played an important role. On the one hand, the chamber of commerce enhances governmental administration by facilitating better communication and accessibility to businesses. On the other hand, it can speak for these enterprises by agglomerating them, and safeguarding their interests. In recent years, the growth of these non-local chambers of commerce has exerted significant influence on China's local economy and society. It is attracting more and more attention from academics and practitioners (Wang, 2010). 
A non-local chamber of commerce refers to an economic association consisting of a group of non-resident merchants who are bound together by geographical loyalty or proximity. In the early stages, these chambers of commerce provided a platform for non-resident merchants from the same places of origin to interact closely with each other. Presently, due to the social reforms in China, intensified market competition, and other factors, these chambers of commerce are facing new challenges to their traditional patterns of organization. In order to break free from the tradition and give full play to their particular intermediary role, many of these chambers of commerce are now looking for new means to innovate their organizational patterns to adapt to the current real macroscopic situation and meet their management demands.

Among these non-local chambers of commerce which are now undergoing operational reform, the Chaoshan Chamber of Commerce in Shenzhen City (CCCSC) is typical. Chaoshan here mainly consists of Shantou City, Chaozhou City, Jieyang City and Shanwei City. The CCCSC, by reforming its strategic basis, financial strategy and organizational structure, started a new model of "businesses run by chambers of commerce" which makes use of the platform provided by the chamber of commerce, thus launching the reform of its organization and taking it on a road to becoming a business entity. It is worth contemplating that the economic interests gained by the CCCSC in "businesses run by chambers of commerce" result in doubts of "contradiction with traditional functions of chambers of commerce". The achievements of the CCCSC in the field of organizational reform have attracted the attention of many scholars. In "The Youth Forum of Chinese Chamber of Commerce in 2014", held in Wuhan, China, the authors of this paper introduced the new developments of the CCCSC, which attracted many senior and young scholars. However, whether this operational model can lead to the new development of contemporary chambers of commerce in their operational models needs further in-depth study.

This research, which applies anthropological methods, explores the organizational reform of the CCCSC. By analyzing relevant investigations, interviews, meeting documents, internal files and second-hand data, this paper points out the developing process of the CCCSC in recent years. This paper further shows the current features of this organization and analyzes its strategic basis, organizational structure, financial strategy, and other real ways of operation such as combination of capitals and cooperation with governments or state-owned enterprises. 


\section{Literature Review}

Presently, there are three major areas of study concerning Chinese chambers of commerce: historical, sociological and economic (Zhu 2004; Wei 2005). Based on historical materials, Zhu (2004) discussed the emergence, development and transition of chambers of commerce as well as guilds and trade associations in China. Zhu then made an analysis of their internal governance structures and described their historical social functions. Xu (1991) studied the Shanghai Chamber of Commerce, and stated briefly that the chamber was established and led by gentry-class merchants who determined its developing direction until it was restructured. Liu (2006), in chronological order and based on other scholars' works, reviewed the origins, features, basic functions, organizational structures and development of Chinese chambers of commerce and their relationships to the capitalist class. She made a contribution to the study of the history of chambers of commerce in China. Wei (2005) overviewed the study of chambers of commerce before 2004, and further discussed their political, economic and social functions, and even their development and systems of organization. Ma and $\mathrm{Fu}$ (2010) summarized the researches that focused on Chinese chambers of commerce in the last 20 years, and classified their new development in the twenty-first century into two parts, with one mainly concerned with the expansion of geographic space and time of study.

Only a few scholars have discussed the governance mechanism of non-local chambers of commerce, especially their financial policies of raising capital and accepting membership fees. According to the different geographical locations of these chambers of commerce studied by the scholars, the Wenzhou Chamber of Commerce, Zhejiang Chamber of Commerce and the Fujian Chamber of Commerce have been the focus of study. These chambers will be briefly presented one by one in the following sections of this paper.

Wang (2004) discovered that the primary source of income for the Wenzhou Chamber of Commerce stemmed from membership fees and sponsorship fees. Its relatively high profits indicate its relative financial independence. Furthermore, Wang (2010), by interviewing several chambers of commerce, found that large enterprises rather than small and medium-sized ones were sources of support for the Wenzhou Chamber of Commerce, and that financial support and profits of the chamber have drawn many excellent, talented people to join the chamber. As a result, the economic strength of the chamber has been increased. In a subsequent study, Yu and Xu (2007) conducted a questionnaire survey of 
the performance of 16 functions of the Wenzhou Chamber of Commerce. They found that owing to its good relationship with the government, it can promote cooperation between the government and business companies on the one hand, and can participate in and discuss government and political affairs on the other. However, Peng (2009), criticized the government-business cooperation model, governance mechanism, and even coverage of members of the chamber. $\mathrm{He}$ emphasized that it might be controlled by large enterprises at the cost of benefits to small and medium-sized enterprises due to "the semi-official" feature of the chamber. In general, researchers found that the Wenzhou Chamber of Commerce expanded its traditional role by safeguarding the rights of new products, and assisting and protecting taxes (Wang, 2004). However, such expansion did not receive support from scholars since it could disadvantage small and medium-sized enterprises (Yu \& Huang, 2004).

Yang and Yang (2010), by studying the internal governance of the Zhejiang Chamber of Commerce, found that its "company-operation model" was an important reference to many other non-profit organizations. Such creative operation models, in the context of the new epoch, can be viewed as important examples of the reform of chambers of commerce in both internal governance and external forms.

Wang (2010), by making a case study of the Fujian Chamber of Commerce, discovered that when chambers and government have common interests, it is possible to form a beneficent interaction between them, driven by mutual interests, thus promoting local economic development. However, this might lead to the formation of a community of interests by government officials and businessmen performing unlawful acts. In contrast to this research finding, Li (2012), after analyzing the history of the Fujian Chamber of Commerce, discovered that it has made increasing progress in its management of daily operations and its construction of democracy. Furthermore, it has broken the restriction on the admission of local resident members. From a diachronic perspective, the literature review shows that scholars have paid increasing attention to the reform of chambers of commerce. From a synchronic perspective, the scholars have studied reforms in the Wenzhou Chamber of Commerce, the Zhejiang Chamber of Commerce, and the Fujian Chamber of Commerce, etc. Though there are a few studies on non-local chambers of commerce, they share the following faults: (1) the scope of these researches is narrow-they have not made a systematic study of the overall development, current situation, and internal mechanism of those non-local chambers of commerce; (2) the 
research methods are not strong enough, lacking investigations with in-depth interviews - most of the research was based on existing documents and records to list and compare data; (3) theoretical study on new problems and issues arising from the development is falling behind in the academic field; and (4) although Chaoshan businessmen are well known all over the world, and Chaoshan chambers of commerce have been set up in many places away from home, there is still no systematic academic study on them from the perspective of management today. This paper focuses on a case study from the perspective of management science. It aims to lay a foundation for the study of organization reform of non-local chambers of commerce, and to provide new experiences of innovating operating models for those chambers of commerce.

\section{Research Methods}

Anthropology is a social science that studies the social environment in which people live, and the impact of this social environment on feelings, attitudes, behavior, and so on (Tian \& Walle, 2009). The ethnographic methodology is one of basic anthropological research methods, which is a process of describing a culture in subjective ways that stem from the feelings of informants who are functioning members of the group being investigated (Tian, 2007). It emphasizes case-study perspectives, focusing on particular periods of a society, particular social groups and particular cultural contexts. In the field of business administration, the ethnographic method is widely used in the study of organizational reform, group behavior, and so on (Tian, 2014; Tian, Van $\&$ Lillis, 2013.). It has accordingly been adopted as the basic research method for this paper.

The other research method is the case study, which can help researchers obtain richness of phenomena (Wieck 2007) and make a further deep description of these phenomena (Tsuen 2007; Tsui et al. 2007). It is the most efficient means of constructing and testing theories, and the primary approach to illustrating "how" and "why". A single case study can help researchers explore new phenomena and problems in management practice, and then make an in-depth case investigation and analysis, and finally answer and test important questions put forth in the research framework. The CCCSC is one such case, with a certain degree of representativeness. This paper, using anthropological-ethnographic methods, makes a single case study of the organizational reform of the CCCSC. The basic research framework is presented in Figure 1: 
Identifying the reform context of CCCSC: the analytical backgroun

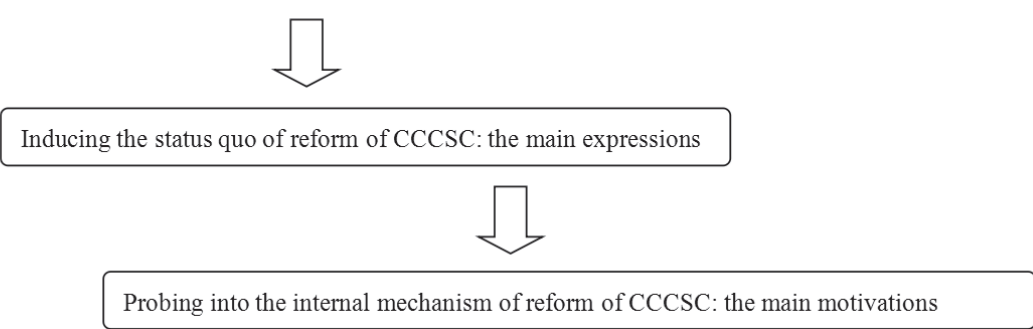

Figure 1. The Basic Research Framework of this Paper

\section{Case Selection}

We chose the CCCSC as the case in this paper for the following reasons: I) the CCCSC has been established for approximately ten years; 2 ) in its initial stages, it started to explore innovative ways to become a business entity; 3) until recently, this model achieved some effects that make it suitable for a case study; 4) as the chosen target of this case study, the CCCSC is representative in four ways:

First, the CCCSC symbolizes non-local chambers of commerce. As one of three traditional Chinese merchant groups, Chaozhou merchants have great influence in the world. In Shenzhen City, there are more than three million Chanshan people, among whom more than one million are businessmen. As we know, Ma Huateng and $\mathrm{Li}$ Jiacheng are representatives of new and old generations of Chanshan entrepreneurs. Chaoshan chambers of commerce have been set up in 26 provinces in China, Hong Kong, Macao, Southeast Asia, North America, Europe, Africa, and Australia. At the same time, the World General Assembly of Chaoshan Businessmen and The World Chaoshan Businessmen Association have been set up as two integrated platforms for all Chaoshan chambers of commerce across the world. In China, except for the Chaoshan merchant group, there is no merchant group owns so many chambers of commerce either in or outside China.

Secondly, the CCCSC is a large and influential chamber. At present, it has more than 2000 member enterprises, three institutional members, and two secondary branches. The CCCSC devotes itself to reporting the opinions and demands of enterprises, and coordinating relations among government, entrepreneurs, and businesses. The CCCSC enhances the connections between Chaoshan businessmen and government offices in 
the Chaoshan region, and among entrepreneurs of chambers of commerce in different places across the world. By doing so, it promotes communication, economic collaboration, science and technology collaboration and information communication between Chaoshan enterprises and others in business affairs. Its member enterprises, with enormous strength, do business in different industries in Shenzhen City, including real estate, construction and installation, financial investment, electronic information, commercial logistics, the gold and pearl industries, and so forth. Owing to its great influence, it has been granted the title of a 5A social organization in Shenzhen City. As a representative of non-local chambers of commerce, the CCCSC has attracted much attention in the academic, commercial and political fields both in China and abroad.

Thirdly, since the CCCSC is located at the "frontier" of Chinese Reform and Opening, it is embodied with innovational ideas. The CCCSC set up a model of "enterprises run by chamber", which uses the chamber as a platform, large enterprises as the operational stage, projects as support, capitals as bond, member enterprises as shareholders, and general dividends to member enterprises as an attractive force. It has thus established a completely new model of running a chamber of commerce.

Finally, the operational model of the CCCSC has achieved some preliminary results. The CCCSC has set up several companies, and is investing in more and more projects. These achievements indicate that CCSC has tentatively realized its plan of becoming a real business entity.

\section{Data Collection}

We collected data for this paper from various sources, including semi-structured interviews, informal interviews, observations, second-hand data, and so on. Through a variety of data-collecting channels, we formed a triangle to measure the data. First-hand materials come from participant observation and interviews, which were obtained in three ways: (1) Interviewing the chairman and the general secretary several times; (2) Informal discussions with some important members; and (3) Onsite investigation and survey conducted by the research team. Additionally, the researchers asked some questions to onsite workers, collected relevant information and sorted out relevant materials. In this study, the researchers investigated the background information of the founding of the chamber, the history of its development, the operation system and the comparison of its past performance. This paper uses these first-hand data to analyze the feasibility and creativity of the CCCSC. The researchers also collected some second-hand materials, which 
mainly included some relevant documents, newspaper reports, and 16 sets of internal materials, and 25 magazines published by the CCCSC.

\section{The Case Study}

In this specific case study, the researchers firstly identified the path of CCCSC development. Understanding the development path of the CCCSC is the basis for further analysis of its organization reform. Then, by interviewing chief secretaries in the chamber, the researchers understood its reform and summarized it into three parts: strategic basis, financial policy, and organizational structure. Finally, based on the understanding of the business operation of the CCCSC, the researchers explored its internal mechanism related to its motivation and resistance and explained the causes that lead the CCCSC to success.

\section{Current Conditions of Non-Local Chambers of Commerce}

In recent years, all sorts of autonomous social groups and organizations have come into being. This is especially true for non-local chambers of commerce which have developed quickly and are highly active. As the registration requirement of non-local chambers of commerce has been lowered, and the government's control has been loosened, non-local chambers of commerce have been set up throughout the country. In some areas, the phenomenon of "more than one chamber in one area" has appeared. As a result, the competition pressures among these chambers have increased, especially for new chambers in Zhejiang Province, Guangdong Province and Shanghai City that are challenging traditional operation patterns.

Besides the substantial increase in quantity, non-local chambers of commerce have undergone profound changes in their operation mechanisms and characteristics. Owing to the tendency of "free membership fee", some non-local chambers of commerce have put forward a creative means to "support chambers by doing business". It is a new idea based on the traditional operation model. Moreover, the organization of chairmen and general secretaries of these chambers has been strengthened. The construction of the chambers has made the cultivation of talent personnel a top priority. The system of selecting a chairman has gradually been changed from "recommended by the higher authorities" to equal competition. Owing to this change in the system, the secretary general is now selected based on quality, competency and professionalism. 


\section{History of the CCCSC's Development}

The predecessors of the CCCSC are the Working Committee of Chaoshan Merchants of the Overseas Economic Promotion Committee of Chaoshan People in Shenzhen City, founded in December 2006, and the Chaoshan Branch of the General Chamber of Commerce of Shenzhen City, established in June 2008. In January 2010, the CCCSC was set up as an independent social corporation, authorized by the Shenzhen Bureau of Civil Affairs.

To make the internal organizational framework better, the CCCSC attempted to build a new model based on the old one. In October 2006, a working committee was set up. In December 2006, the constitution of the chamber regulations was approved, and the first chairman was elected. At same time, the Committee of Qualification Inspection was established. In March 2007, the Chaoshan Investment Management Company was established, which symbolizes the beginning of the business operation of the CCCSC. In September 2012, the Committee of Strategy Making was set up, and four economic entities affiliated to the chamber were established one by one (see Table 1).

\section{Table 1: Enterprises Run by The CCCSC}

\begin{tabular}{|c|c|}
\hline Name & Major work \\
\hline $\begin{array}{l}\text { 1. The Petty Loan } \\
\text { Company of } \\
\text { Chaoshan Merchants } \\
\text { in Shenzhen City }\end{array}$ & $\begin{array}{l}\text { It provides short-term loans for small and } \\
\text { medium-sized companies, mainly in production, } \\
\text { manufacture, sale, service industries, and some } \\
\text { new entrepreneurs. }\end{array}$ \\
\hline $\begin{array}{l}\text { 2. Equity \& Fund } \\
\text { Investment } \\
\text { Company of } \\
\text { Chaoshan Merchants } \\
\text { in Shenzhen City }\end{array}$ & $\begin{array}{l}\text { Set up and invested by all member stockholders, it } \\
\text { provides plans and consultation for equity } \\
\text { investment, strategic investment, and stock } \\
\text { marketing. }\end{array}$ \\
\hline $\begin{array}{l}\text { 3. The Investment } \\
\text { Group Limited of } \\
\text { Chaoshan Merchants } \\
\text { in Shenzhen }\end{array}$ & $\begin{array}{l}\text { It concentrates on the establishment of a } \\
\text { cooperation platform among Chaoshan merchants } \\
\text { in the world, mainly in real estate, urban } \\
\text { infrastructure, banking business, investment of } \\
\text { new technology, and investment in cultural and } \\
\text { educational fields. }\end{array}$ \\
\hline
\end{tabular}




\begin{tabular}{|c|c|}
\hline $\begin{array}{l}\text { 4. Investment } \\
\text { Consultants Limited } \\
\text { of Chaoshan } \\
\text { Merchants in } \\
\text { Shenzhen City }\end{array}$ & $\begin{array}{l}\text { It engages professionally in investment and asset } \\
\text { management. It is an important platform for } \\
\text { Chaoshan merchant group to raise capital and } \\
\text { manage assets. }\end{array}$ \\
\hline
\end{tabular}

The CCCSC has vigorously carried out many investment projects in order to obtain co-opted operation of capital. From 2007 to 2008, the CCCSC chose four investment projects, including the CBD central financial area, Yuejiaotan Plot, the Central Park Program in Chengong new district, and the renewal program of Wuhua old district in Kongming City. When the first land auction in 2014 was held in the Qianhai District of Shenzhen City, Qianhai International Energetic \& Financial Center in Shenzhen City held by Chaoshan Merchants Group, allied with Silverstein Properties from the USA, obtained that openly auctioned land in Shenzhen-Hong Kong Cross Border Cooperation Zone at a cost of RMB13.4 billion.

The organizational scale of the CCCSC has gone through a gathering procedure from small to large. In March 2007, only 40 people attended the first the CCCSC board of directors meetings. Then in June 2008, nearly 200 people attended the Session of Director Congress, which was also the ceremony of the founding of the CCCSC under the Shenzhen General Chamber of Commerce. Today, there are over 500 CCCSC senior officials, including an honorary president, strategic decision-making committee members, an honorary adviser, executive committee members, chairman, vice-chairman, executive members, and directors and so on. In May 2014, the CCCSC elected a new chairman, and a new-generation board of directors with the new objective of "big Chaoshan, close cooperation, great development".

\section{Three Parts of the Business Operations of the CCCSC}

By making an analysis of the interviews, meeting materials, internal materials and second-hand data, this paper found that the business operation of the CCCSC mainly involves three parts: strategic basis, financial policy and organizational framework (shown in Figure 2). 


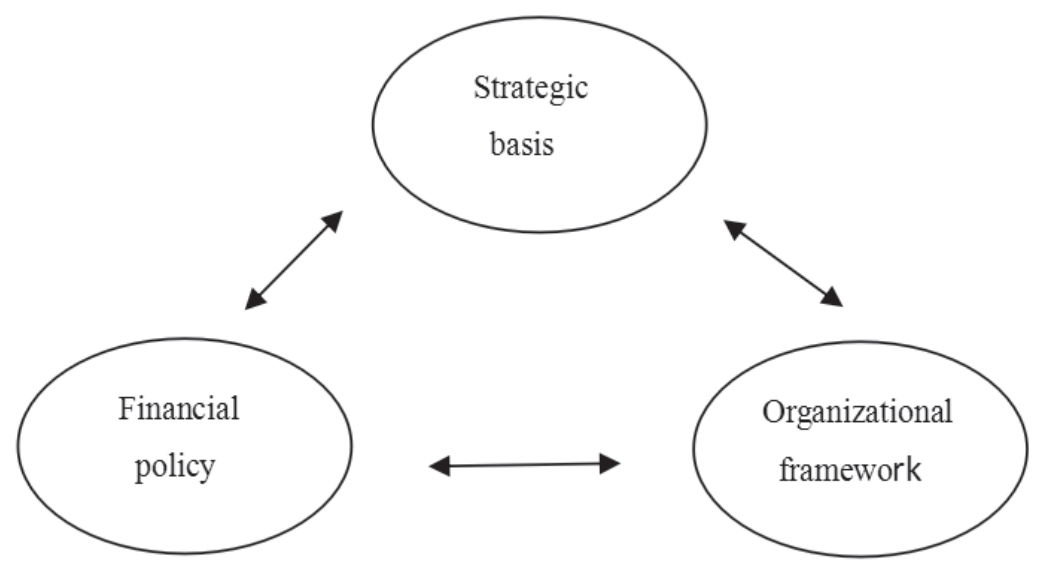

Figure 2. Three parts of the Business Operation of the CCCSC

The researchers found that the strategic decision-making committee, established by the CCCSC, provides the organizational basis to formulate, carry out, and subsequently modify all kinds of its policies. The CCCSC, as a large organization, has 130 chairmen and vice-chairmen, 200 executive directors and 150 directors. It is impossible that the board of directors can exercise its leading power efficiently. Hence, the strategic decision-making committee, as the core institution of the board of directors, deliberates on important investment projects first, and then submits it to the board of directors; this can avoid wastage of resources. It can also prevent errors caused in the process of transmission of information. Thus, it can improve working efficiency, and the implementation of these strategic measures can lead the CCCSC to formulate its aims, carry out its specific strategies, and strongly push the reform of business operations. The researchers found out that the construction at the strategic level is the precursor of the CCCSC in realizing its aims to become a real business entity (organization reform).

Financial policy is the core work of the CCCSC, which adopts business operational measures and invests widely in different types of enterprise. This innovation in investment and fund-raising is the core and the most characteristic part of the business operation of the CCCSC. With the help of this platform of chambers of commerce, merchants can set up economic entities. The income from investment and financial management is enough to solve the normal expenditure of the CCCSC. Compared with the expenditures of the CCCSC, the expenditures of 
traditional chambers of commerce are mainly from membership fees, donations and government funds. This indicates that the capital-raising measures of the CCCSC are innovative. It solves the problem of capital, making the CCCSC more independent in its operation. It reflects the progress of autonomous rights that the chamber of commerce has made in social fields, and deserves to be studied in the academic field. The researchers believe that the CCCSC's financial policy in investment and fund raising is at the core of its business operations (organizational reform).

The design of the CCCSC's strategies and the implementation of its financial policies are closely related to its organizational framework. The organizational structure of an enterprise needs to adapt to strategic development, as does that of the chambers of commerce. Through analysis of documents, the researchers found that there are some distinct differences between the CCCSC and traditional chambers of commerce in terms of organizational establishment.

The board of directors of the CCCSC is the leading institution, and whose members are the core leaders of the chamber. As the highest authority, the member conference votes its chairman and directors according to its constitution and the principle of democratic centralism. The board of directors consists of key entrepreneurs from Chaoshan merchants in Shenzhen City, who are highly influential in many industries.

In the CCCSC, most of the financial, social, material and information resources belong to the board of directors. The board of directors also owns the decision-making rights, voting-rights, review rights and rights for final judgment regarding all important issues of the CCCSC. This group-power mechanism expresses the opinions of the majority of the members, and guarantees the right development direction of the CCCSC. At the same time, it safeguards the common interests of all the members. Besides these organizations, the CCCSC sets up the supervisory board, and the strategic decision-making committee. 


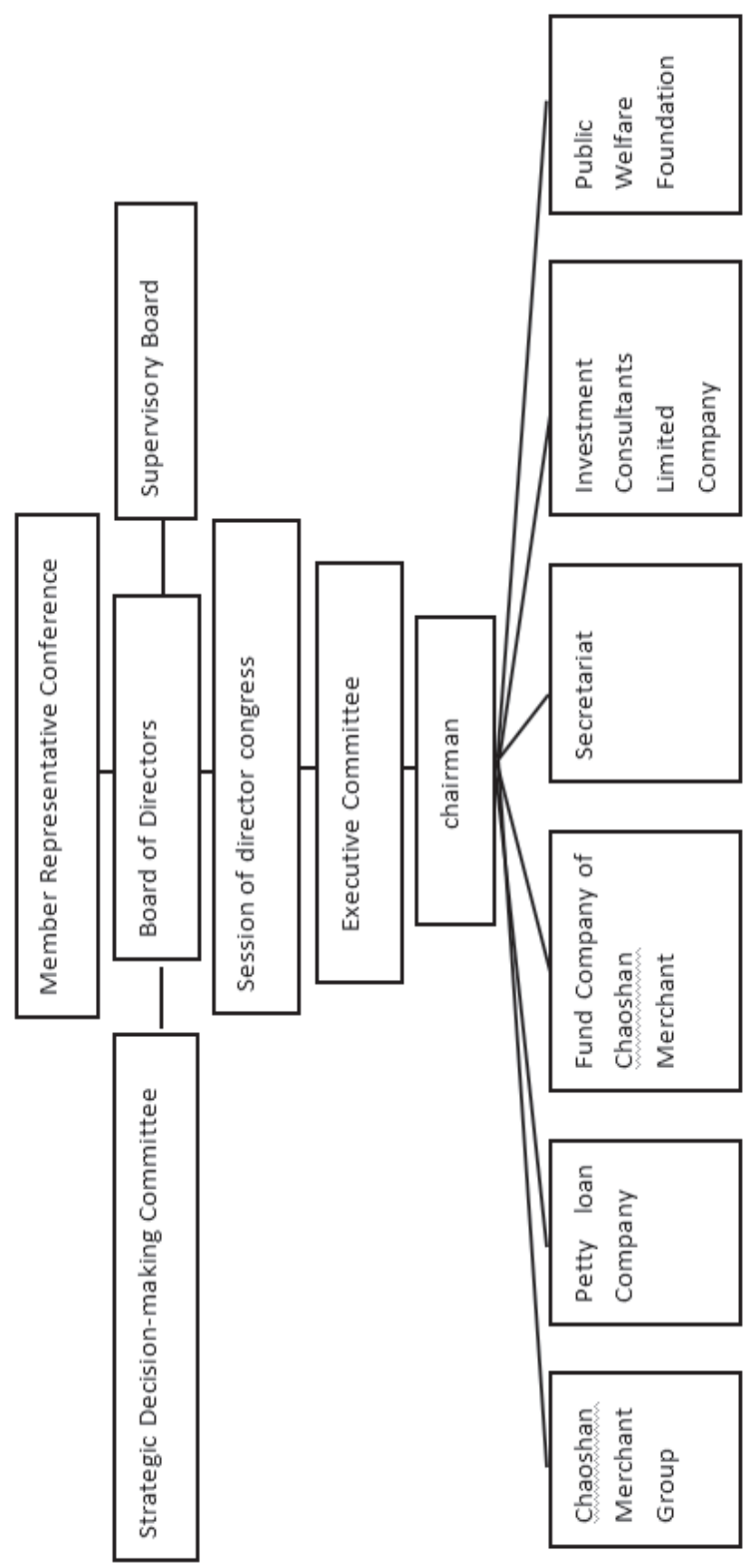

Figure 3. The Organizational Framework of the CCCSC 
The core feature of the CCCSC's organizational framework is that it attempts to create benefit equilibrium for all participants. The CCCSC, as an integral-interests entity, needs to realize such benefit equilibrium among its branches while each of its own branches (Shaotou Chamber of Commerce, Jieyang Chamber of Commerce, Chaozhou Chamber of Commerce and Shanwei Chamber of Commerce) is self-financing, and is set up according to the features of these enterprises. The CCCSC and its branches allow their members to cross-hold membership. Further, they support each other and do not conflict with each other's internal affairs, thus enabling the interests of these organizations to be more closely connected. It is this organizational framework that has allowed the CCCSC to develop successfully. Therefore, the researchers believe that the new organizational framework of the CCCSC is its important support of organizational reform (business operation).

By analyzing various data, the researchers found that these three parts of the organizational reforms of the CCCSC interconnect. The strategic construction promotes the operational reform of the chamber, and the investment to build entity enterprises, creative means of fundraising, and other financial policies are the expressions of the core contents of organization reform. In this process, the new organizational framework ensures the implementation of this organizational reform. The interconnection and dialogue among these three parts lead the CCCSC to realize the leap-forward development and breakthrough.

\section{The Internal Mechanism of the CCCSC}

The description of the three parts of the organizational reform above reflects the CCCSC's current situation. If this paper made a conclusion on the basis of a single case study, it would inevitably contain faults and be hard to generalize from. In order to reduce such faults to the minimum, and understand this case study better, this paper will discuss the CCCSC's organizational reforms and their internal mechanisms, to search for the impetus and resistance it faces, and to further explain the causes for its achievement (see Figure 4). 


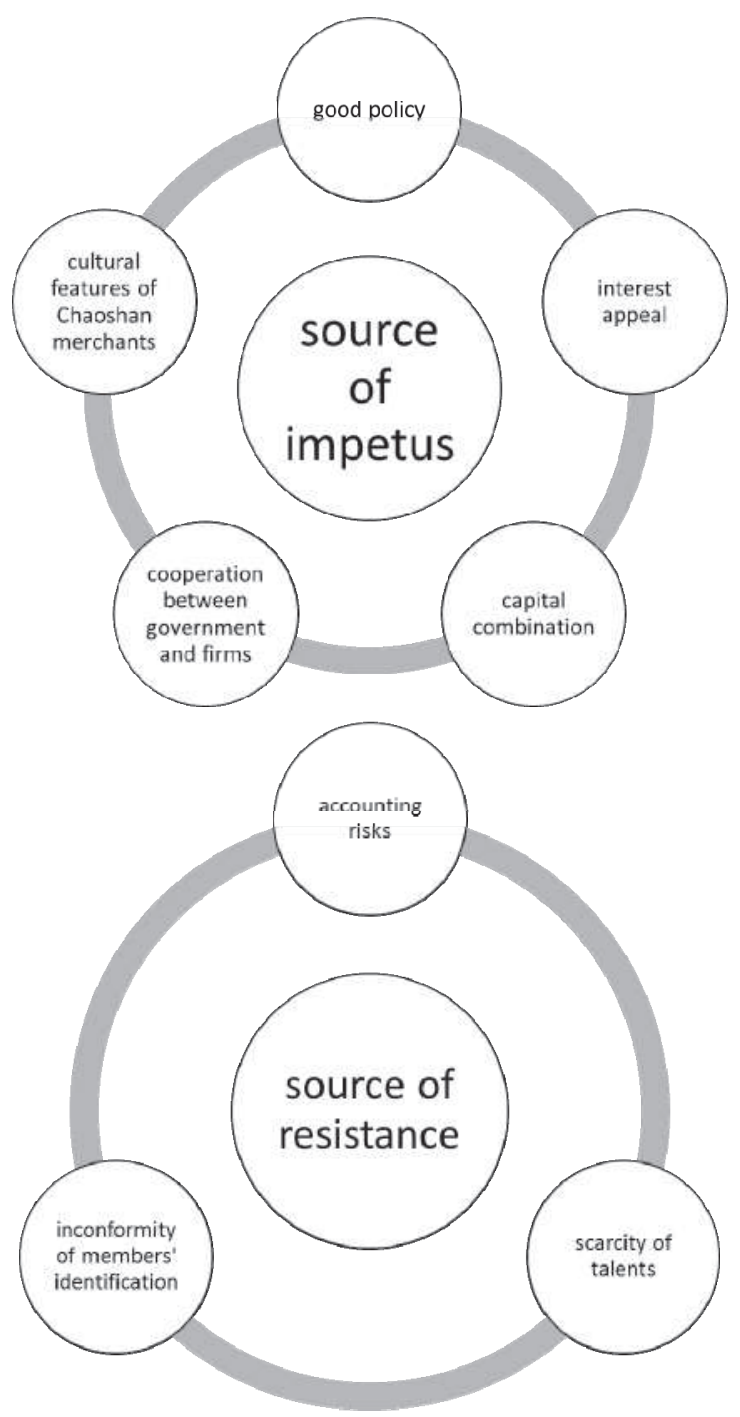

Figure 4. the sources of power and resistance in the reform of the CCCSC 


\section{The Sources of Impetus}

The impetus of the creative operational model of the CCCSC is derived from various sources such as:

1) Good Policy

The Chinese government encourages the development of chambers of commerce: this is the external environment of the CCCSC's reform. In recent years, the government has adopted more flexible policies regarding the establishment of social organizations, and is gradually abandoning control over market intermediary organizations. By doing this, it has helped chambers of commerce to promote their organizational competence and to provide more services to their members. The social macro-environment is in favor of creativity and the development of chambers. Accordingly, better development is not just experienced by the CCCSC: other chambers in other cities have also begun to flourish.

2) The Cultural Personalities of Chaoshan Merchants

Cultural personalities of Chaoshan merchants provide the CCCSC with ideological support and a cultural basis to conduct its reform. As one of three large traditional merchant groups, the Chaoshan merchant group has survived over five hundred years and has become one of the most influential, as well as one of the wealthiest chambers within the Chinese diaspora. Chaoshan merchants are always united when facing the external world. Although most merchants from other places do the same thing, Chaoshan merchants perform more distinctively. When doing business in other places, Chaoshan merchants tend to emphasize lineage relationships, a blood relationship and geography, and expand their social networks with the support of their chambers of commerce. The Chaoshan merchants' group unity is the key to their success in running businesses. It is their unique brand: the Chaoshan Chamber of Commerce is thus like a brand on behalf of all Chaoshan merchants. It can raise a large amount of operational capital and attract talented businessmen from every walk of life. It can integrate sources through collaboration and communication by all group members. It can also promote risk-taking ventures - the culture of Chaoshan merchants encourages Chaoshan merchants to be pioneers. .

3) Appeal of Benefits

The direct motivation for the CCCSC's reform is the appeal of benefits, which forced the chamber to carry out important reforms in fundraising, investment and other financial strategies. The appeal of benefits is a process in which social subjects pursue self-interest and then engage in relevant social activities in order to gain benefits (Wang 2010). 
So if the chamber lacks funds, it cannot carry out its commercial plans.

Through reform, the chamber can achieve the balance and unification of all shareholders. Consequently, on the one hand, it can promote group cohesiveness and further strengthen the ties of all members, while on the other, it can motivate members to join the chamber and work together to promote prosperity of the chamber.

From the economic perspective, the appeal of benefits is the essence of all things. Although it is a non-profit organization, the chamber needs to guarantee and improve benefits for all parties. The appeal of benefits exists extensively in a variety of chambers. If such appeals can be mobilized, it can inspire internal reform power and can greatly help the chamber to build the business operational mechanism.

As a non-profit organization, the chamber should mainly provide services to its members rather than directly obtaining income. On its platform, the chamber starts its investment which has some financial risks. If the project could not be carried out well or the capital chain ruptured, it would bring risk to the whole Chamber. However, the creativity of this operational model is that members can raise funds on this platform and freely organize to set up investment companies instead of the chamber carrying out such projects under its own name. Accordingly, the CCCSC now has four real businesses that belong to their shareholders. The chamber does not hold direct ownership and has no direct interest relationship with the profit or loss of these companies.

4) Capital Combination

Capital combination is a necessary means for the CCCSC to reform and a necessary safeguard to sustain the chamber's development. Today's market competition depends on capital. So capital combination is the direction of economic development. In Shenzhen City, there are more than one million Chaoshan merchants, who have accumulated capital to different levels. According to the estimates of the CCCSC, the total assets of Chaoshen merchants in Shenzhen City are valued at several thousand billion RMB. However, the limited assets of individual persons can decrease the efficiency of wealth operation, and information communication is also restricted in each aspect. Hence, only by combining can a large financial group be formed with economic strength that enables it to take an advantageous position in market competition. It can also improve the efficiency of using the idle funds of member enterprises. When the chamber initiates an economic entity, its fundamental aim is to integrate Chaoshan merchants' wealth for a great collaboration to run large and important projects. 
5) Cooperation between government and enterprises

The main purpose of the CCCSC reform is cooperation between government and enterprises. The new model of the CCCSC is a negotiation mechanism, which can stimulate communication and exchanges between enterprises and the government, thus building a cooperative relationship between them. The chamber can use collective force to report appeals of benefits by a group to the government, and as a community of common interests, it can fight with relevant government departments in order to protect its own interests (Nie, 2010). The second point of Article 7 in Chapter Two of the Chamber's constitution is: "to report members' opinions and demands, and to bridge the communication between members and government." As an economic entity deriving from the unity of Chaoshan merchants, the CCCSC can provide a platform to launch investment which has more advantages in cost and competition.

First of all, in comparison with medium-sized and small firms, the enterprises of the CCCSC have better internal mechanisms that follow the state uniform accounting regulation to ensure that all accounting materials are legal, true and accurate. Their normalized and programmed operation of projects is favorable both to lobby the government and to publicize governmental supervision.

Secondly, the effective disclosure of information can give the Chamber a higher credit-rating. The operational situations of enterprises and accounting information should be transparent in the Chamber. As a result of this, government and enterprises are equal in receiving information, and the credit cost is relatively low.

Thirdly, because the Chamber can draw upon the wisdom of many excellent entrepreneurs, it can help its members to quickly grasp business opportunities in a changing market. Besides, the Chamber has great financial support: when an investment project runs into high risks, the government is more willing to choose the chamber to handle them.

\section{Sources of Resistance}

The Chamber faces a great deal of resistance, and even more so when it is looking for reform and business operation. The researchers found out that major sources of resistance are from accounting risks, and lack of talented personnel.

1) Accounting Risk

The researchers found that accounting risk is one of major risks that the chamber encounters. On the one hand, the existence of these risks 
can improve the reform of the chamber, but on the other, reform always results in accounting risks.

By nature, the chamber is an intermediary service organization, and cannot itself be an economic entity. The so-called business operation of the chamber is in fact that by means of this service platform, the chamber can initiate its members to make investment, and then set up investment companies. The Chamber thus has no right to strictly supervise enterprises under its control, and its operational efficiency is not high. Another problem is that once the Chamber starts making profits, members may want to take advantage of it.

The business operation of chambers of commerce is still being explored in China. There are not presently laws or regulations for effective supervision by the Ministry of Civil Affairs, which is in charge of supervising chambers of commerce. Fiscal charges and accounting items are difficult to supervise, because support systems have not implemented.

2) Inconformity in Members' Acceptance

In the investigations, the researchers found that there were many members who dissented from the Chamber's reform: they disagreed with the operational method that some "big bosses" in the chamber take the lead in undertaking big projects. There are three major reasons for this. First of all, they are suspicious of enterprises operated by the Chamber. They believe that the fundamental function of a non-local chamber should be to provide services for its members, and to strengthen the friendship among its members. In general, it should be a platform to provide information to its members. On the contrary, the business operation of a chamber might blur its function, and the chamber may become a large profit-making financial group. Secondly, from the government's perspective, the government allows the establishment of chambers as a way to transmit its policies and as a way to propagate healthy social activity. However, the performance of the reformed chamber is inconsistent with the government's original purpose. Thirdly, members of the chamber do not have equal rights. Chambers always consciously choose resources and adopt strategies (Yu, Xu and Jiang 2014). If the chamber chooses one or more enterprises as its core sponsors, these enterprises will become its real decision-makers. In the CCCSC, the membership fees are determined by members' positions, which in turn decide their rights of speech. This may lead to inequality. When high profits are involved, the chamber might fall apart.

To such problems, the CCCSC has put forward preliminary solutions. It now uses multi-approaches and multi-perspective ways to provide 
services to member enterprises. When different opinions arise in project investment, the Chamber will hold project-by-project discussions, and adopt one model for one project approach. It will promote investment on multiple levels and in multiple areas to increase member participation.

3. Lack of Talent

Wu (2006) stated that it is necessary to professionalize operational staff in chambers of commerce. There are two reasons. First of all, since each entrepreneur has his/her own company, he/she is so busy that he/she cannot perform his/her duties in the chamber well. Secondly, it can prevent the conflict between the chamber's interests and each entrepreneur's interests. Due to the shortage of managers, it is very difficult to professionalize managers in the CCCSC.

The growth of social automatic forces is closely linked with the promotion of social elites, who are not only the basic forces in the framework of state systems, but also the important social forces to promote social integration and to form self-organization and order in a society (Chen \& Ma, 2004). Human resource is the core of enterprises. Creative talented personnel can be major factors that affect the development of chambers of commerce. At present there are many problems in the management teams of chambers in China, such as small numbers, an aging population, and inferior quality. The lack of talented managers has become an increasingly urgent issue. With the government adopting more flexible registration policies, the competition among chambers will become fiercer. Some chambers, due to their poor service capability, cannot attract talent and will lose their senior managers sooner or later. It will further reduce their capacity to provide good service, which leads to the scarcity of finance personnel and the loss of employees. As a result, the vicious cycle of chambers' operation may appear.

Hence, no matter whether it is for humanitarian reasons or in pursuit of greater efficiency, the chamber should pay more attention to the intelligence of its employees. By decentralizing power and authority, the chamber can create more opportunities for its employees in order to establish an atmosphere of open and mutual trust in the organization, thus contributing to the construction of a "learning" organization ( $\mathrm{Yu}$, $\mathrm{Xu}, \&$ Jiang, 2014).

The researchers identified that accounting risks, inconformity of members' acceptance and scarcity of talents are the major sources of resistance in the business operation of the CCCSC. 


\section{Discussion and Conclusion}

The reform of the CCCSC has three integral parts: strategic management, accounting strategy, and organizational framework. The strategic construction is the precursor of business operation (organizational reform), which powerfully pushes the reform of the business operation of the CCCSC. The core of a business operation is the investment and fundraising of the CCCSC (accounting policy), which is mainly demonstrated in the investment to build business enterprises, the innovative means of fundraising, and other accounting policies. The new organizational framework of the CCCSC is the backbone of its organizational reform (business operation), which makes the framework adapt to the strategy and provides a safeguard to the implementation of the organizational reform.

The driving force of its innovative operational model comprises five factors: good policy, Chaoshan culture, capital combination, appeal of benefits, and cooperation between government and enterprises. At the same time, the reform has to overcome three factors of resistance: accounting risk, limited support from members, and scarcity of talented personnel.

Non-local chambers of commerce set up economic entities by using its platform. This action is not antipathetical to the established functions of these chambers, which act as an intermediary organization between government and enterprises. Its non-profit organizational feature determines that it cannot be constructed as a monetization-tool to directly gain profits. There is a new breakthrough to this problem in the CCCSC. It can both keep the traditional functions of the chamber, and put out new measures to serve its members. In the field of organizational reforms, there is very few research on non-local chambers, a type of non-profit organization. This paper has attempted to rectify such deficiencies and shortages. The current research is based on single-case analysis in which there are some shortages. The research conclusions may not be adoptable in other situations. Nevertheless, if other chambers can learn from the spirit of the Chaoshan operational model, they might improve the reforms of their own chambers.

\section{References}

Bun, \& Kwan.M. (2012). Modern China's Network Revolution: Chambers of Commerce and Sociopolitical Change in the Early Twentieth Century. American Historical Review: 177-178. 
Chen,S.Y., \& Ma.B. (2004). The Private Board of Trade of Wenzhou: an Analysis of the Self-administrative System. Management World, 12(12): 31-48.

Giurgiu. A.M., Manciu, I., \& Lese, I. (2016). Technological Development-A Tool for Social and Economic Impact of the Chamber of Commerce and Industry of Mures County. Procedia Technology, 22:1092-1099.

Hui. E.S., \& Chan. C.K. (2014). The politics of labor legislation in southern China: How foreign chambers of commerce and government agencies influence collective bargaining laws. International Labor Review, 153: 587-607.

Hon, T.K. (2013). Modern China's Network Revolution: Chambers of Commerce and Sociopolitical Change in the Early Twentieth Century by Zhongping Chen (review). Journal of World History, 24: 240-242.

Li, C. (2012). The Management System of Remote Chambers: Current Situation, Problems and Countermeasures. Gansu Social Science, 2: 236-239.

Liu, F. (2006). Review to The Study of Chinese Chambers of Commerce in the Latest 20 Years. History Teaching and Research, 4:84-93.

Liu, H. (2009). Chambers' Features, Revolution and Institutional Arrangement. Beijing: China Social Sciences Press.

Ma, M., \& Fu, H.Y. (2010). The Last Twenty Years of Research on Chinese Chambers of Commerce 1990-2009. Modern Chinese History Studies, 2:126-142.

Nie, L. (2010). Play a Role of Chambers of Commerce, Cultivate its Economy. China Collective Economy, 11:27-28.

Song, M. (2002). The Chamber of Commerce in Modern Tianjin City. Tianjin: Tianjin Social Sciences Press.

Tang, Y. (2009). The Study of Chamber of Commerce (Federation of Industry and Commerce) Transition, Shanghai Journal of Economics, 9: 108-116.

Tian, G. (2014). Economic Anthropology with Chinese Characteristics: Yang Tingshuo Xiangji (Interphase) Operational Theoretical Model. The Anthropologist, 17(2): 311-318.

- (2013). Paradigm of Economic Anthropology in China: Academic Thought of Yang Tingshuo's Interphase Operational Model. Journal of China Mizu University, 40(5): 11-16.

Tian, G., Trotter. D., \& Liu,Y. (2015). Anthropological Methods are Meaningful in Business Research: A Case Study of Foodservice at a Chinese University, The Anthropologist, 19 (1): 11-24.

Tian, G., Van Marrewijk. A.H. \& Lillis, M.H. (2013). General Business Anthropology. 2th Edition. Miami FL: North American Business 
Press.

Tian, R. (2005). From theory to practice: Anthropology in business education. High Plains Applied Anthropologist, 25(1) 12-28.

Tian, R. G. (2009). Anthropology and business education: Practitioner applications for a qualitative method. International Journal of Management Education 7(2): 59-67.

Wei, W. (2005). One Hundred Years' Chambers Viewed from today. International Academic Development, 4: 4-7.

$\mathrm{Wu}$, J. (2006). The Positioning of Chambers of Commerce and Self-governance. China Reform, 10:29-32.

Xie, S. L., \& Hu, G. (2012). The Periodic Analysis to the Cultural Features of Chaoshan Merchants. Business Culture, 5: 329-330.

Xie, S.L., \& Chi, X. D. (2012). The Management of Public Relationship Between the Culture of Chaoshan Merchants and Enterprises. Business Culture, 9: 161-163.

Wang, S. (2004). The development of third department and prospect of civility society: example of Wenzhou Chamber of Commerce. Journal of Public Management, 4:34-40.

Wang, H. (2010). The Interactive Mechanism between government and Businessmen in the Development of Remote Chambers of Commerce. Economic Herald, 12: 36-37.

$\mathrm{Xu}$, Y. Q. (2005). Folk chamber of Commerce and local governance: theoretical basis and foreign experience, Journal of Zhejiang provincial Party School of the CPC Central Committee,5:19-24

Yang, J. P. \& Yang, X. H. (2010). A study on the operation mode of non governmental organizations in China - a case study of the Zhejiang chamber of Commerce, Modern management science, 10:46-48

Yu, B. (2012). The New Chapter of Reform of Chaoshan Chamber of Commerce in Shenzhen City. Chaoshan Businessman, 5: 1-5.

Yu, J. \& Huang J. (2004). The automatic governance and limits of Chamber of Commerce: example of Wenzhou. Journal of Zhejiang Party, 5:5-16.

Yu, J., Xu, Y., \& Jiang, H. (2014). The Development of Chambers of Commerce in the Period of Comprehensively Deepening Reform and Opening. Beijing: Higher Education Press.

Yu, J. H., Xu, Y. Q., \& Jiang, H. (2007). Is the Case of Wenzhou Industrial Association Exceptional in the Chinese Context? Development and Challenges of China's Civil Society. Journal of Zhejinag University (Humanities and Social Sciences), 37(6): 5-14.

Yao, Z., \& Yuan, Z. (2012). The General Analysis to the Modal of Chamber of Commerce and its Functions. Legal System and Society, 
$2: 182-183$

Yu, J., Zhou, J., \& Zhang, J. M. (2014). The Development of Business Associations During the Era of Comprehensively Deepening Reform in China. Beijing: Higher Education Press.

Zhu, Y. (1990). The Study to the New Merchants Organization During the Revolution of 1911. Beijing: China Renmin University Press.

\section{Acknowledgments}

This research is sponsored by National Social Sciences Foundation of China (14BGL130), Social Sciences Fund of Guangdong Education Department (2013WYXM0044), Social Sciences Fund of Shaotou University ( SR12003). 